\title{
Urgences
}

\section{et en sortant...}

\section{Lévis Dumais}

Numéro 13, mars 1986

\section{Éclats d'atelier}

URI : https://id.erudit.org/iderudit/025230ar

DOI : https://doi.org/10.7202/025230ar

Aller au sommaire du numéro

\section{Éditeur(s)}

Urgences

\section{ISSN}

0226-9554 (imprimé)

1927-3924 (numérique)

Découvrir la revue

\section{Citer ce document}

Dumais, L. (1986). et en sortant... Urgences, (13), 67-70.

https://doi.org/10.7202/025230ar

Ce document est protégé par la loi sur le droit d'auteur. L'utilisation des services d'Érudit (y compris la reproduction) est assujettie à sa politique d'utilisation que vous pouvez consulter en ligne.

https://apropos.erudit.org/fr/usagers/politique-dutilisation/ 


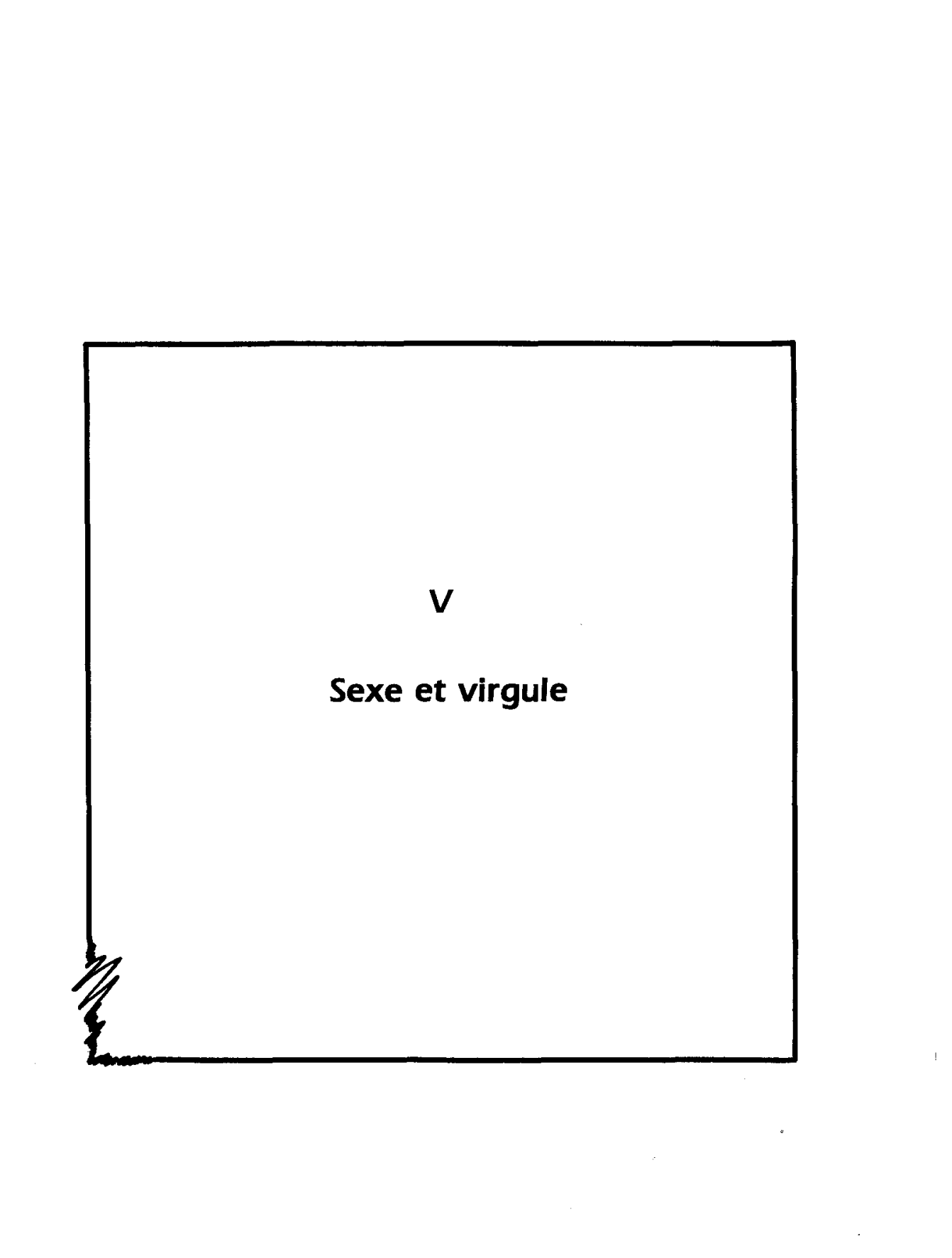




\section{Postulats: sexe et virgule}

Écrire un texte d'une seule phrase pointée d'un seul signe de ponctuation et qui affirme ouvertement, entre le puritanisme et le sexualisme permissif, son désir de fouiller telle "question sexuelle", effet de langage.

Sexe - voir Guy Scarpetta: L'impureté, coll. "Figures", Paris, Grasset, 1985, p. 309 et ss. 


\section{Lévis Dumais}

et en sortant du bar, il lui prit la main et sentit déjà la chaleur qu'elle dégageait, chaleur qui, il en était sûr, irait en augmentant au fur et à mesure que leur relation allait évoluer, surtout lorsqu'ils arriveraient à son appartement où, rendus là, il l'aiderait à enlever son manteau en l'embrassant dans le cou et en lui disant qu'elle sent merveilleusement bon, il la ferait asseoir sur son sofa, il lui servirait un petit cognac en s'installant tout près d'elle et en posant une main baladeuse sur sa cuisse, tout en continuant la conversation qu'ils auraient entreprise depuis un bon moment et qui aurait contribué à faire augmenter leur excitation qui ne serait pas loin de son paroxysme lorsqu'ils poseraient leur verre sur la table du salon pour engager un long et tendre baiser. tout d'abord en se léchant sensuellement les lèvres pour ensuite laisser leur langue librement suivre leurs fantasmes, s'embrassant tout le visage, le cou, les oreilles, les yeux, le nez, haletant et gémissant, sans oublier de se caresser mutuellement et de plus en plus intensément, il choisirait cet instant pour la prendre sur ses genoux, pour doucement lui ouvrir son corsage et lui presser légèrement les seins dont il savait la peau encore plus douce que ce qu'il avait senti auparavant, il laisserait sa langue courir le long de son cou, de son épaule qu'il aurait découverte, et il s'attarderait longuement sur le délicat mamelon en érection. mais sans oublier de se délecter de toute sa poitrine, de ses bras, de ses aisselles, de son ventre, de son nombril, de ses hanches, de son pubis qu'il mettrait habilement à nu malgré un jean trop serré, ses mains, l'une dans son dos pour l'étendre lentement, l'autre continuant de voyager sur tout son corps, dévêtissant en caressant, découvrant petit à petit des formes qui l'auront toujours fait vibrer de fascination, sa langue poursuivant ses expériences tactiles sur ses cuisses, sur ses fesses, revenant entre ses cuisses, évitant intentionnellement de répondre trop vite aux lèvres invitantes qui remueraient imperceptiblement, comme dans un murmure, mais pas trop longtemps quand même, parce qu'il aurait sûrement une envie folle de s'abreuver à cette 
source de plaisir qu'il savait intarissable, mais dont il ne pouvait se nourrir ce soir-là, étant hors de ses principes de se donner à la première rencontre, surtout qu'elle lui plaisait beaucoup et qu'il était sûr qu'elle comprendrait s'il lui exposait son point de vue sur la question, qui était de ne pas en arriver là, s'ils en avaient la volonté et la force 